\title{
La construcción de la identidad política de un nuevo candidato electoral: espacios discursivos e imagen social en el discurso de Pablo Iglesias
}

Nieves Hernández Flores

Universidad de Copenhague

\section{Introducción}

Este trabajo tiene como objetivo estudiar la construcción discursiva de la identidad política de un candidato electoral. El interés se centra en el discurso del político español Pablo Iglesias en los inicios de su carrera (en 2014), apenas unos meses después de la fundación de su partido, Podemos (el I7 de enero de dicho año), y en plena preparación de la campaña electoral a las primeras elecciones a las que concurría, las europeas del 25 de mayo ${ }^{\mathrm{I}}$. El análisis, de tipo cualitativo, se centra en una intervención de Iglesias de nueve minutos y medio durante un acto público con simpatizantes de su partido, en el cual expone algunos puntos clave del ideario político y electoral que manejaba en esa primera etapa de su carrera. Como marco teórico se emplean dos aproximaciones: por una parte, el análisis del discurso desde una perspectiva cognitiva permite identificar y describir los espacios discursivos (Zupnik I994) construidos por el político en su alocución; por otra parte, se recurre a la sociopragmática para mostrar las actividades de imagen realizadas (Hernández Flores 20I3a), según los efectos sociales de su

\footnotetext{
${ }^{\text {I }}$ Otros trabajos que recientemente han analizado el discurso de Iglesias son los de Hernández Flores (2015), sobre la creación de identidad política a través de un blog digital; Ærstrøm (2015), sobre la descortesía en debates televisivos, con inclusión de lo no verbal; Bernal (20I6) sobre actividades de imagen en la comunicación metadiscursiva mediada en el marco parlamentario (conversación entre pasillos con presencia de cámaras); y Alcaide Lara (en este volumen) sobre el carácter populista de la argumentación y retórica de Pablo Iglesias en su discurso parlamentario.
}

Cómo citar este capítulo:

Hernández Flores, N. 2019. "La construcción de la identidad política de un nuevo candidato electoral: espacios discursivos e imagen social en el discurso de Pablo Iglesias”. In: Françoise Sullet-Nylander, María Bernal, Christophe Premat \& Malin Roitman (eds.). Political Discourses at the Extremes. Expressions of Populism in RomanceSpeaking Countries. Stockholm Studies in Romance Languages. Stockholm: Stockholm University Press, pp. 223-24I. DOI: https://doi.org/Io.I6993/bax.k. License: CC-BY 
discurso en su propia imagen y la de sus destinatarios de acuerdo con los roles desempeñados (Bravo 2002, 2005).

Pablo Iglesias, doctor en Ciencias Políticas y anteriormente profesor de la Universidad Complutense de Madrid, es el líder de Podemos, un partido posicionado en la izquierda republicana que se caracteriza por su desmarque de las formas y contenidos políticos tradicionales, con una actitud abiertamente crítica hacia los organismos de poder (especialmente políticos y económicos) a los que achaca ser los causantes de la crisis económica y social de España durante la última década. Por su lado, Podemos se presenta como un partido que tiene entre sus objetivos manifiestos devolver el poder al pueblo, para lo cual plantea modificar, o incluso desmontar, parte de los mecanismos del Estado ${ }^{2}$. Por este posicionamiento rompedor ha sido calificado con frecuencia como populista (cf. los trabajos de Bernal y Alcaide Lara en este volumen)3. Durante el período 20I4-20I7, Podemos participó en cuatro comicios electorales a nivel nacional, llegando a situarse como la tercera fuerza más votada; de hecho, ya en su primera participación (las elecciones europeas de 20I4) alcanzó un sorprendente resultado para un partido nuevo, siendo el cuarto más votado, con un $7,9 \%$ del total de votos y 5 escaños, un resultado más sorprendente aún por el hecho de que no se realizó una campaña electoral al uso, es decir, el partido no llegó al electorado mediante mítines masivos, carteles publicitarios o aparición en los medios de comunicación de más difusión (la televisión pública o los grandes diarios españoles). Por el contrario, su campaña se realizó a través de las redes sociales (Twitter y Facebook), de programas de televisión de elaboración propia emitidos por internet, y mediante su participación en debates con periodistas y políticos de diferentes tendencias en dos cadenas privadas de televisión. ${ }^{4}$ Estos

2 Tales como someter la monarquía a votación o permitir la celebración de referendos independentistas, lo que supone la modificación de la Constitución española.

3 Sin embargo, el posible populismo del discurso de Iglesias no es objeto de investigación en el presente trabajo, habiendo optado por el estudio de sus características discursivas e ideológicas sin adentrarme en un propósito mayor como sería la discusión de su eventual pertenencia a la categoría de discursos populistas.

${ }_{4}$ Las apariciones de Iglesias en televisión comenzaron en 2003 , pero fue a partir de mayo de $20 \mathrm{I}_{3}$, seis meses antes de fundar el partido, que se hicieron más frecuentes, especialmente en programas de debate de difusión nacional como La Sexta Noche (La Sexta Tv), Las mañanas de Cuatro (Cuatro Tv) e incluso una aparición de gran repercusión en 2013 en el programa de debate El gato al agua de la cadena Intereconomía Tv, conocida por su tendencia conservadora (para algunos, de extrema derecha). Además, cuenta con los programas de producción propia 
programas, o vídeos con extractos de los momentos más polémicos, fueron colgados en Youtube, de forma que la repercusión fue aún mayor. Su líder, con gran capacidad oratoria y manejo de los medios, tuvo ocasión de difundir ampliamente su mensaje, lo que incrementó tanto su popularidad que incluso se utilizó una imagen de su rostro como logotipo del partido en la papeleta electoral de esas primeras elecciones.

Pues bien, es en este período previo a la primera participación de Podemos en unos comicios en que se sitúa el interés del presente trabajo, por ser el momento en que, dada la apenas inexistente experiencia de Iglesias en el campo de la política activa (que no como ideólogo, donde tenía una amplia formación como profesor e investigador), su identidad política aún estaba en construcción. A la hora de observar el discurso de Iglesias en los inicios de su carrera, nos encontramos con dos tipos de datos. Por una parte, el discurso dirigido a la gente a través de su participación en debates televisivos, con un propósito persuasivo y electoral. Por otra, un discurso interno dirigido a personas comprometidas políticamente, en concreto a compañeros de partido o de ideología, en el cual Iglesias muestra sus conocimientos y creencias, es decir, un discurso donde desnuda su ideario político, apartándose de las limitaciones y las presiones del ámbito mediático (los programas televisivos donde se dio a conocer ante la opinión pública).

En este discurso de base es donde se pueden contemplar los fundamentos de donde surgió Podemos: por una parte, una ideología de izquierdas que constituye su planteamiento político; por otra, las circunstancias políticas, económicas y sociales de España de los últimos años, donde se ha creado un contexto de desconfianza, desengaño y protesta por parte de la ciudadanía hacia sus dirigentes, no solo por parte de ciudadanos de una determinada militancia política, sino del conjunto de la población española. Es, por tanto, a estas circunstancias a las que se adapta el discurso de Iglesias desde el momento en que junto con otros correligionarios deciden crear un partido de izquierdas y presentarse a las elecciones.

En este contexto político y social, y a la hora de construirse una identidad política, Iglesias combina dos fundamentos: por una parte, posicionarse ideológicamente en la izquierda ${ }^{5}$, también frente a los par-

La Tuerka (entrevistas realizadas por Pablo Iglesias) y Fort Apache (programa de debate dirigido por él).

5 El concepto de ideología manejado en este trabajo se basa en la relación entre discurso, cognición y sociedad (Van Dijk 2006). 
tidos de izquierda tradicionales españoles, y, por otra, lo novedoso de su propuesta: tratar de incorporar a la parte del electorado español que no tiene un firme compromiso político o que incluso si lo tiene no es de izquierdas, pero que se ve afectado por la situación de crisis en España. Esta construcción discursiva de una identidad política propia está íntimamente relacionada con la imagen social del candidato, la cual se define de acuerdo con los roles adoptados en su discurso (por ejemplo, los roles de líder político o de izquierdista, entre otros).

La relación entre la identidad política construida en el discurso y los efectos de imagen social producidos por este será el objeto de discusión en el análisis de un extracto de la charla de Iglesias.

\section{Marco teórico}

Dentro del análisis del discurso desde perspectivas cognitivas, la propuesta de Zupnik (I 994) ${ }^{6}$ se basa en el concepto de frame de Goffman (I974); el de campos de la experiencia -worlds of experience- que Chafe (1979, I980) identificó en las narraciones de argumentos de películas; y el concepto de espacios mentales de Fauconnier (I985). Zupnik aborda los procesos discursivos que llevan al uso de determinados elementos lingüísticos, es decir, los espacios producidos en un determinado marco, en el que se incluyen los roles interaccionales desempeñados. Los procesos discursivos desarrollados establecen nuevos espacios y pueden referirse a otros ya conocidos, constituyendo espacios discursivos, 'discourse spaces' (Zupnik I994: 34 I-342). Los espacios discursivos son, por tanto, dominios de realidad que constituyen el centro de atención del discurso, y pueden referirse tanto al mismo evento comunicativo en que se producen (por ejemplo, en el discurso político, referencias a la situación creada durante una entrevista, un debate o un mitin) como a dominios creados mediante narraciones del enunciador, o a otros más abstractos que configuran el espacio discursivo político.

Sean del tipo que sean, estos espacios están limitados por un conjunto de expectativas, basadas en experiencias, en torno a estos tres elementos:

\footnotetext{
${ }^{6}$ Estudios que han aplicado la propuesta de Zupnik (I994) al análisis del discurso político en español, y en concreto al uso de la deixis, son los de Blas Arroyo (2000); Hernández Flores (2013 b); Hernández Flores y Gómez Sánchez (20I4) y Mariottini (2015).
} 
- las coordenadas espacio-temporales

- las acciones y eventos que se desarrollan en ellas

- los roles de los participantes en las mismas.

Identificar y describir los espacios, por medio de estos elementos, permite contar con un marco de análisis en el que realizar las interpretaciones de los fenómenos discursivos que intervienen en la configuración de ideologías, pero además permite explicar los mecanismos de persuasión propios del discurso político. La persuasión, según Zupnik (I994), se logra mediante dos estrategias: mediante el movimiento del hablante por los diferentes espacios discursivos y roles creados por él/ella (lo cual le permite manejar los discursos a su interés, justificarse ante lo polémico o dirigir la atención del destinatario hacia donde le conviene); y mediante la inclusión de los destinatarios en los espacios propios del hablante, creando lazos de solidaridad con ellos/ellas.

Pues bien, ambos tipos de movimientos suponen unas actividades comunicativas que tienen unos efectos sociales entre los interactuantes, unos efectos ya observados por Zupnik (1994) en algunas estrategias. Así, la estrategia de la justificación (por ejemplo, ante una actuación polémica del hablante), la cual se realiza manejando los espacios y roles discursivos, trataría de proteger la imagen social de este; la estrategia de la inclusión del destinatario en la perspectiva del hablante, con el fin de crear lazos de solidaridad, puede repercutir favorablemente en la imagen social propia y en la ajena. Para ahondar en esta cuestión, veremos las actividades de imagen que suponen la realización de estas estrategias.

Las denominadas actividades de imagen en estudios sociopragmáticos (face-work, Goffman I967) se refieren a la repercusión social de los comportamientos comunicativos en una interacción dada (cf. Bravo 2002; Hernández Flores 2002, 2013a, 2015; Bernal 2007). En concreto, a la repercusión de estos en la imagen social ( $f a c e$ ), una necesidad psicosocial que se considera intrínseca al ser humano y que se ve afectada en los intercambios comunicativos por el comportamiento verbal y no verbal realizado. ${ }^{7}$ Con esta base se han escrito teorías de cortesía (como la famosa de Brown y Levinson I987) así como estudios sociopragmáticos en torno a lenguas y comunidades culturales

7 El concepto de imagen manejado en el presente trabajo es, por tanto, el concepto de imagen social ('face'), de carácter psicosocial y estudiado en la comunicación por la sociopragmática (a diferencia de conceptos como imagen pública, usados en otras tradiciones teóricas). 
específicas, al considerarse que la imagen social no es universal, sino variable culturalmente. En el caso del español, los estudios de Bravo (por ejemplo, I999, 2002) han propuesto dos categorías para abarcar el concepto: la imagen de autonomía, referida a la necesidad de la persona de diferenciarse de su grupo; y la de afiliación, referida a la necesidad de sentirse parte de un grupo. Esto supone unas características generales de la imagen social que se concretan en cada comunidad específica de acuerdo con los valores compartidos. Pero, además, la imagen social se adapta a la situación específica en que se encuentra el hablante en el momento comunicativo, dando lugar a la llamada imagen del rol de los hablantes (Bravo I996, I999, 2002; Hernández Flores 2013a; Bernal 2007, 2016; Alcaide Lara 2014; Pano Alamán 2015, entre otros). De esta forma, en el discurso político de Pablo Iglesias se esperaría encontrar la imagen de rol de politico, de militante de izquierdas, de profesor universitario, etc., lo que se refiere a cómo se ve y desea verse la persona en esos roles. Por ejemplo, en el rol de político, ser una persona al servicio de su comunidad; en el rol de izquierdista, vigilar por los derechos laborales de los trabajadores; como profesor universitario, tener unos conocimientos y una opinión crítica hacia los temas, etc. Todas estas imágenes de rol son parte de la imagen social personal del propio individuo (su imagen individual), la cual puede estar dirigida a su necesidad de autonomía (por ejemplo, mostrar la validez y solidez de sus propuestas políticas) o a su necesidad de afiliación (por ejemplo, mostrar compromiso con su comunidad). Mediante comportamientos discursivos como refrendar la validez propia y confirmar el servicio a la comunidad, el político confirma, por tanto, su imagen de autonomía y su imagen de afiliación en ese rol. En añadidura a esta imagen social individual, la persona, como miembro de un grupo con el que se identifica, posee a su vez un deseo de imagen de grupo. En el caso de un político, su imagen de grupo le puede llevar a presentar comportamientos comunicativos de defensa de las cualidades de este frente a otros grupos (imagen grupal de autonomía), además de otros comportamientos que muestran la cohesión y confianza existentes dentro del propio grupo (imagen grupal de afiliación) (cf. Bravo I999, 2002; Bernal 2007, 2016).

Pues bien, los encuentros comunicativos (debates, pero también alocuciones) son lugares donde el discurso del hablante crea efectos sociales en la imagen de sus interlocutores y de sí mismo (Bravo I996, 2002, 2005; Hernández Flores 2013a). Estos comportamientos comunicativos con efecto social constituyen las actividades de imagen, las 
cuales, según Hernández Flores (20I3 y y 20I 5), pueden ser de cortesía, cuando el efecto es positivo para la imagen de ambos interactuantes; de descortesía, cuando es negativo; o de autoimagen, cuando el efecto positivo recae sobre la imagen del mismo hablante o del propio grupo. ${ }^{8}$

\section{Metodología y datos}

El texto elegido para estudiar la configuración de la identidad política de Pablo Iglesias a través de su discurso es un extracto de una charla ofrecida el 5 de febrero de 20I4 en la Sala Mirador, de Madrid, con el título ¿Qué es una democracia real? En esta intervención, el candidato responde a una pregunta del presentador del acto sobre «el secreto de Pablo Iglesias» y explica a los asistentes, con un estilo informal y cercano, cuál es su estrategia electoral de cara a los ciudadanos y su actitud hacia el izquierdismo, lo que supone una autorreflexión sobre la propia estrategia y la actitud política y electoral. Se trata de una modalidad de discurso diferente de la utilizada por Iglesias en sus comienzos políticos, y que le dio a conocer: intervenciones preparadas en programas televisivos de gran audiencia, con temas polémicos y frente a contertulios y periodistas críticos hacia él. La charla elegida para el análisis, sin embargo, se caracteriza por la improvisación, el marco informal y familiar (el público son simpatizantes de izquierdas) y la difusión "casera" por medio de un vídeo colgado en Youtube. Por otra parte, la respuesta a la pregunta sobre «el secreto de su éxito» está condensada en apenas diez minutos, lo que supone un ejercicio metadiscursivo donde es el propio político quien reflexiona sobre su estrategia política y electoral, sobre su discurso y sobre la imagen que quiere dar a los ciudadanos, lo que supone un texto de gran interés para propósitos de análisis discursivo y sociopragmático. La charla, de nueve minutos y medio de duración, es accesible a través de Youtube ${ }^{9}$, fue transcrita por mí misma y dio lugar a un corpus de 1.693 palabras.

${ }^{8}$ Observemos que esta aproximación a las actividades de imagen desde la tradición sociopragmática presenta semejanzas con conceptos de otros marcos teóricos como, dentro de los estudios de argumentación y retórica, el concepto de ethos del enunciador (Charaudeau 2005, 2009), referido a la imagen pública que crean en su discurso los actores políticos, mostrando su lucidez y dominio, y buscando así la credibilidad y la persuasión que los lleve, finalmente, a ser aceptados por el público (Charaudeau 2009: 290).

9 http://www.youtube.com/watch?v=Yizw-RySZnI 
El análisis del texto consiste en identificar los elementos que construyen el espacio discursivo mediante las categorías de coordenada espacio-temporal, de acciones y eventos, y de roles, para analizar cómo se relacionan entre sí a la hora de crear esos espacios, y así conseguir la persuasión (cf. Zupnik I994). El segundo objeto de interés será ver las repercusiones sobre la imagen social propia y la de los demás (su propio grupo, y los otros grupos) de las actividades comunicativas empleadas en la construcción de este espacio discursivo.

\section{Análisis}

\subsection{Los espacios discursivos del discurso de Iglesias}

Desde la aproximación de Zupnik (I994), el texto se muestra con varios niveles discursivos: el del evento comunicativo (la charla política, con alusiones a la propia intervención y a la audiencia); el que constituye la explicación sobre la estrategia política; y, en relación con este, un tercer espacio creado a partir de narraciones de anécdotas y situaciones vividas, lo que supone incorporar discursos atribuidos a otras personas (tanto contrincantes como políticos afines) en la construcción de un espacio discursivo político propio. Los elementos que configuran el espacio discursivo político de esta intervención se han reflejado en la tabla I.

Empezando por las coordenadas espacio-temporales, como decía más arriba, de carácter cognitivo, el espacio en el que se sitúa Iglesias (marcado en negrita) es de cuatro tipos:

a) el espacio político electoral al que concurre:

(I) toda nuestra actividad politica se ha dedicado a pensar cómo podemos ganar [las elecciones] (I:IO) ${ }^{\mathrm{IO}}$

b) el espacio de los medios de comunicación:

(2) cómo podemos ganar utilizando el principal instrumento de socialización política [...] que son los medios de comunicación (I:I2-I3)

c) el espacio de la izquierda política:

(3) a la gente de izquierdas [...] nos gustan nuestros simbolos politicos, (3:I I)

Io Los números entre paréntesis identifican la página (primera cifra) y la línea (segunda cifra) de la transcripción de donde se ha obtenido el ejemplo. 


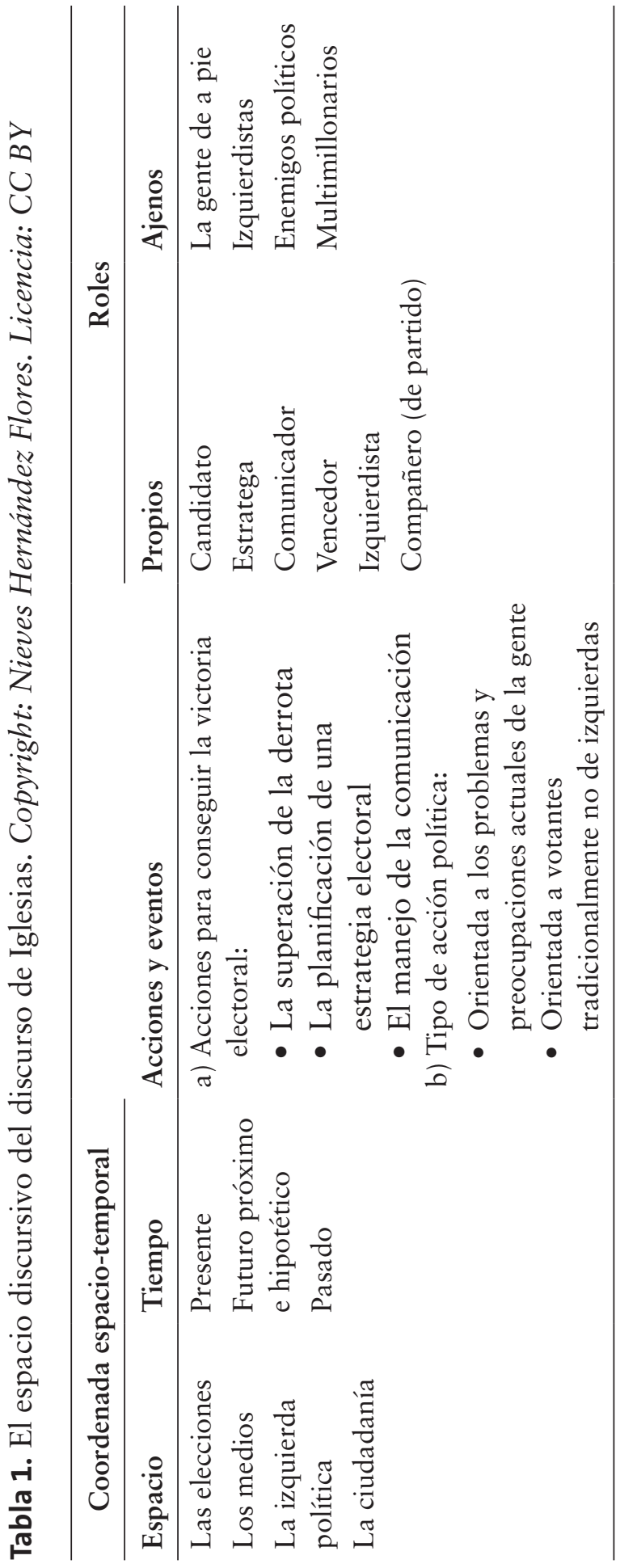


d) el espacio de la ciudadanía:

(4) otro día me paró un policía por la calle (2:27).

Esos cuatro espacios principales están ligados a una coordenada temporal centrada en el presente:

(5) En todos los debates en los que intervengo me reúno con los compas de Podemos y hay una discusión continua, ( $\mathrm{I}: 20-2 \mathrm{I})$

y a un futuro próximo, hipotético pero esperanzado, de victoria:

(6) Si convencemos a esta gente (...), igual ganamos. Y yo quiero ganar. (3:I-2). Hay también una alusión al pasado, el de la historia política de su familia:

(7) a mi abuelo le condenaron a muerte, ( $1: 3-4)$

y al pasado de la izquierda:

(8) en un contexto de derrota ideológica total en el que nos han insulta'o, nos han criminalizado $(3: 4-5)$.

En estas coordenadas espacio-temporales se realizan unas acciones o eventos, algunos principales y otros subordinados a estos. La acción principal en este fragmento es la del logro de la victoria electoral. El objetivo de ganar (o bien de no perder), y otros sinónimos aparecen mencionados 23 veces a lo largo de la intervención. Es una acción que está ligada al espacio electoral y a un tiempo futuro inmediato, pero también está condicionada por un pasado personal y político donde el acto destacado era la derrota:

(9) Y tengo la derrota, tatuada en mi ADN ( $\mathrm{I}: 3$ ).

Este espacio pasado de derrota es lo que estimula a Iglesias a conseguir ahora la victoria:

(Iо) que no te derroten otra vez (4:I4).

Los otros actos mencionados están relacionados con este principal de lograr la victoria electoral, en concreto, hay una acción de planificación de estrategia electoral que constituye el medio para lograr la victoria:

(I I) Si convencemos a esta gente [...], igual ganamos. (3:I-2)

y el procedimiento es el manejo de la comunicación, como le aconsejan sus compañeros de partido en la preparación de sus intervenciones: 
( 2 ) 'Podias diseñar cuatro cositas como tú no manejas mal lo de la comunicación' (2:I)

lo cual realiza en equipo:

( 13 ) me reúno con los compas de Podemos y hay una discusión continua (I: 2O-2I).

Ligado también al acto principal de conseguir la victoria electoral, está la acción política, que se caracteriza por tener una orientación hacia la gente, a su malestar y a su esperanza, pues la victoria

(I4) tiene que ver con la rabia de la gente, con la ilusión de la gente, tiene que ver con llegar a la gente [...].

La selección de esa gente con la que se busca un acercamiento se hace mediante la creación de un nuevo espacio discursivo a base de reproducir anécdotas e historias narradas donde las personas representadas proceden de áreas sociales tradicionalmente alejadas de la izquierda, como las fuerzas de seguridad o los votantes conservadores. Este espacio discursivo de narraciones se compone de la carta que recibió Iglesias de una mujer militar cuyo contenido desvela el orador en su intervención:

( 15) Y me decía: 'ese concepto de patria que manejas, en el ejército... lo comparte mucha gente' (2:24);

una anécdota propia de un encuentro con un policía en la calle:

( 16) Y otro día me paró un policía por la calle [...] para decirme, 'soy un policía municipal y estoy de acuerdo con lo que usted dice' (2:27-30);

o con votantes del partido más alejado de su propuesta, el conservador Partido Popular (PP):

( 17) Yo estoy deseando que se me acerquen señoras que digan, y ocurre y eso me emociona un montón: 'Yo voté al PP pero me parece que lo que dices, tienes razón’ (3:18-20).

Sin embargo, es interesante señalar que estas acciones (las acciones políticas para conseguir la victoria electoral) no aparecen solo en el espacio discursivo de las elecciones, sino que están en relación con el espacio de la izquierda política, de forma que cada una de estas acciones del espacio de las elecciones se contrasta con las acciones de ese espacio de izquierda política. Así, si en el espacio de las elecciones, la acción se caracteriza por la lucha por la victoria, esto se pone en contraste con 
la acción en el espacio de la izquierda tradicional española, caracterizada por el objetivo menos ambicioso de solo mejorar ligeramente los resultados electorales, como se puede ver en el siguiente ejemplo (en los ejemplos de aquí en adelante la acción de Iglesias se marca en negrita y la de la izquierda tradicional se subraya).

(18) Y yo quiero ganar. No quiero ser el $20 \%$. No quiero ser el I $5 \%$. No quiero que mi máxima aspiración política sea arrancarle tres consejerías al maldito Partido Socialista. $(3: 2-4)$.

Si el procedimiento para conseguir la victoria es manejar la comunicación, en ese aspecto también se diferencia Iglesias de los grupos tradicionales de izquierdas, pues él no tiene reparos en debatir en programas televisivos de contenidos polémicos y populares, a falta de una mayor presencia de las organizaciones de izquierda en los medios:

(19) el hecho de que tenga que dar un paso adelante un tipo con melena que discute en la televisión con Marhuenda ${ }^{11}$... [...] no es normal. Si estuvieran organizadas, los sindicatos, las organizaciones sociales, no harian falta cosas como estas.

Iglesias ha conseguido introducirse en un campo, el de los medios, al que estos grupos han tenido hasta el momento un acceso restringido:

(20) Mi presencia en los medios de masas, [...] un territorio absolutamente hostil en el que la derrota ideológica e incluso física de los que venimos de la izquierda es total. ( $\mathrm{I}: \mathrm{I} 3-\mathrm{I} 6)$.

En esa estrategia de llegada al electorado a través de los medios no está solo, sino que cuenta con el respaldo de un equipo y acepta sin miedo sus opiniones, lo que contrasta con un supuesto miedo de la izquierda tradicional a la crítica dentro del partido:

(2I) no tener miedo a tus propios compañeros. En todos los debates en los que intervengo me reúno con los 'compas' de Podemos y hay una discusión continua.

Pero donde Iglesias se posiciona de manera destacada frente a sus compañeros de ideología es en la acción política, en concreto en cuanto a

II Se refiere a los debates televisivos con periodistas como Francisco Marhuenda, director del diario conservador La Razón. Iglesias se refiere a sí mismo con la imagen por la que es popularmente conocido: un tipo con melena. 
la selección de la parte de la población a la que se demanda el voto, un electorado alejado tradicionalmente de la izquierda:

(22) para ganar, la izquierda tiene que dejar de ser una religión y convertirse [...] en un instrumento en manos de la gente, tiene que convertirse en pueblo.

(23) La gente de izquierdas [...] estamos convencidos que juntando cuatro siglas en un cartel eso supone que vamos a ganar. Y iqué va!, iqué va, iqué va! Tiene que ver con otra cosa. Tiene que ver con [...] llegar a gente que de otra manera nos vería como marcianos.

De ahí que se incorporen al espacio discursivo las narraciones de estas gentes tradicionalmente alejadas de la izquierda. Es el caso de la narración de la mujer militar, quien en su carta le dice:

(24) He encontrado más compañerismo y camaradería en el ejército que en la $\mathrm{UGT}^{\mathrm{I2}}{ }^{\mathrm{2}}$ 2: $\left.\mathrm{I} 4-\mathrm{I} 5\right)$

y de la anécdota con el policía municipal o con las votantes del partido conservador. Una acción, por tanto, creada en un espacio discursivo propio (el de Iglesias), diferenciado del espacio discursivo tradicional de la izquierda, lo que conlleva una crítica implícita a esta, como se verá más adelante.

Finalmente, como se ve en la tercera columna de la Tabla I, estas acciones crean unos roles: Iglesias asume para sí mismo principalmente el de vencedor, no de simple candidato, sino de candidato vencedor, lo que en la coordenada espacial de las elecciones le da también un rol de estratega, y en relación con la coordenada espacial de los medios, de comunicador. En la coordenada espacial ideológica, desempeña un rol de militante de izquierdas, que en relación con otros militantes le da el de compañero de partido.

Asimismo, Iglesias crea roles para los que le rodean. Por una parte, los de compañeros y militantes de izquierda, ampliamente nombrados a lo largo de la intervención, aunque, como hemos visto, no es hacia ellos que va dirigida su acción política, sino hacia un grupo social más amplio que le lleva a crear otro rol: el de la gente, calificada por el hablante como la gente decente, aunque Iglesias no desarrolla más este rol a lo largo de su intervención. Frente a ellos, los contrincantes políticos, especialmente de derechas, tienen el rol de enemigos, y los que controlan los medios de comunicación son los multimillonarios, aunque

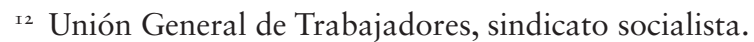


en este discurso no son roles tan relevantes en relación con las acciones como son los otros.

Por lo tanto, mediante el manejo de estas coordenadas cognitivas interrelacionadas de tiempo, espacio, acciones y roles, el político crea un espacio discursivo propio cuya característica, como ya describió Zupnik (1994) y ha sido mostrado en otros análisis, es de dos tipos. Por una parte, Iglesias muestra su capacidad de moverse por diferentes espacios discursivos (el espacio discursivo electoral y el ideológico), lo que le permite adaptarse a los diferentes receptores, expectativas y, además, justificar sus acciones (su participación en debates televisivos y su atención a los no votantes de izquierdas, entre otros). Pero, además, puede realizar alianzas con los destinatarios y así construir relaciones de solidaridad. En este caso, la incorporación de Iglesias se dirige a sus compañeros de izquierda mientras que la gente de a pie (sus denuncias, reivindicaciones sociales o protestas), muy presentes en sus intervenciones televisivas, no tienen tanta presencia en esta ocasión, seguramente por no ser los destinatarios de su alocución; de hecho, aparecen nombrados la mitad de veces que los militantes de izquierdas ( Io casos frente a 20), siendo desplazados hacia un uso instrumental: son la llave para conseguir la victoria. Por el contrario, la alianza principal se pretende con los militantes de izquierdas, a los que se trata de incorporar al espacio discursivo del proyecto político. Desplazarse dentro del discurso y manejar los roles permite así al político alcanzar la persuasión.

\subsection{Las actividades de imagen de Iglesias}

Los movimientos por los espacios discursivos analizados más arriba están relacionados con las actividades de imagen realizadas, y en ese sentido, en este extracto de discurso, estas actividades son de varios tipos. Por una parte, las actividades comunicativas consistentes en incluir al rival político en el espacio discursivo propio para otorgarle el papel de antagonista, lo cual se hace mediante la elección léxica en la denominación (enemigos) y de la deixis de tercera persona (el i i \% del total de deixis personal en el texto $\left.{ }^{13}\right)$. Estas estrategias comunicativas suponen una actividad de autoimagen para reafirmar frente al otro la imagen de grupo, en este caso la de un hablante con el rol de miembro de grupo político de izquierdas; por el contrario, cuando se alude al grupo donde están incluidos políticos del Partido Popular y el Partido

\footnotetext{
${ }^{13}$ De un total de 2 I 8 pronombres personales y morfemas verbales de persona.
} 
Socialista, así como los propietarios de los medios de comunicación (denominados multimillonarios), el término acuñado es sinvergüenzas que en el sentido de 'el que comete actos ilegales' en este contexto entraría en el terreno del insulto no esperado entre políticos, lo que nos llevaría a hablar de descortesía. El efecto social de la actividad descortés es de daño en la imagen del otro (los miembros de ese grupo), al tiempo que sirve al hablante para reforzar su imagen individual de cara a su propio grupo (cf. Bolívar 2005).

Por el contrario, cuando Iglesias introduce en su espacio discursivo a compañeros de militancia política (crea para ellos el rol de militante de izquierdas y compañero), la actividad de imagen es de cortesía. Por una parte, hay estrategias de atenuación en las críticas que dirige a sus propios compañeros, dirigentes actuales y, sobre todo, viejos dirigentes de la izquierda. Esto lo realiza mediante dos recursos principales:

Por una parte, la impersonalización en la designación de los miembros de ese grupo se realiza mediante su inclusión en grupos e instituciones, sin nombrar personalmente a nadie:

(25) la Izquierda tiene que dejar de ser una religión y convertirse en un instrumento.

(26) si estuvieran organizadas, los sindicatos, las organizaciones sociales.

Por otra parte, el uso de la deixis de primera persona del plural de tipo inclusivo:

(27) ¿Por qué no tratamos de entender que la mayor movilización que se ha producido en este país [...] no ha tenido que ver con una decisión politica de las organizaciones de izquierdas?

(28) [...] revela nuestra maldita debilidad, el hecho de que tenga que dar un paso adelante un tipo con melena que discute en la televisión con Marhuenda [...].

Ambas estrategias de atenuación tienen un efecto de cortesía porque permiten proteger la imagen social del destinatario, el grupo de la izquierda política española, de un posible daño que la crítica produce a su imagen social de autonomía en el rol que Iglesias le otorga al grupo (combatientes políticos). Al mismo tiempo, estas estrategias de atenuación le permiten a Iglesias proteger su propia imagen social individual, evitando el riesgo de parecer prepotente de cara a su propio grupo, lo que consigue incluyéndose en el grupo que critica. Obsérvese que, además, en este uso de la deixis el enunciador evita la primera persona del 
singular $\left(y_{0}\right)$ para referirse a sí mismo, prefiriendo una forma nominal de tercera persona, un tipo con melena que discute en la televisión, que aparentemente le resta protagonismo, en lo que supone una actividad de autoimagen de atenuación de su propia autonomía (consistente en ser modesto, no tratar de destacar por encima de los demás).

Por tanto, los lazos de solidaridad creados por Iglesias con sus destinatarios (simpatizantes y militantes de grupos de izquierdas) se realizan a través de estrategias de atenuación de posibles amenazas a la imagen de este grupo, lo que constituye una actividad de imagen de cortesía.

Finalmente, en este contexto, igual que ante los roles y espacios discursivos creados, el pueblo, la imagen social de la gente a la que va dirigido el mensaje político, no adquiere relevancia.

\section{Conclusión}

Con este análisis detallado de la configuración de espacios discursivos de un candidato electoral he tratado de adentrarme en cómo es la construcción de un ideario político a través del discurso. En esta construcción es fundamental la situación que presenta la imagen social propia, individual y grupal, y la que se presenta de los demás.

Hemos visto que es fundamental tener en cuenta quién es el destinatario principal del discurso; en ese sentido, como el propio Iglesias dice, un discurso dirigido a la gente de a pie, como el de los programas televisivos, se plantea de forma diferente. Este, sin embargo, tiene como destinatario principal a compañeros y simpatizantes de izquierdas, y por ello crea una serie de espacios que van desde un espacio ideológico tradicional y muy politizado, donde estaría la vieja izquierda de grandes ideales que nunca llega a proclamarse victoriosa en contiendas electorales, y una izquierda igualmente cargada de ideología pero con un objetivo pragmático, que es el defendido por Iglesias: acercarse a un electorado mayoritario que no es de izquierdas, pero al que, debido a un contexto de crisis política, social y económica, con la corrupción en primer plano, se puede acceder mediante ideas de izquierdas. En este orden de cosas, las actividades de imagen (cortesía, descortesía, autoimagen) que aparecen en su discurso operan en doble sentido. Por una parte, complementan la finalidad de construir una ideología propia, en una función que puede ser de refuerzo en la creación de espacios y de roles; pero, además, las estrategias pragmáticas utilizadas (justificación, atenuación, creación de lazos de solidaridad) producen actividades de imagen con efectos sociales en la propia imagen del hablante, en la de su grupo y en la de 
grupos ajenos, permitiendo al político posicionarse socialmente de cara a los demás y configurar así un espacio social propio en el que situar su ideología. Una discusión más profunda sobre esta ideología, así como la evolución experimentada hasta el momento político actual, con su presencia en el Parlamento, serán futuro objeto de investigaciones.

\section{Bibliografía}

Alcaide Lara, E. R. (20I4). «La relación argumentación-(des) cortesía en el discurso persuasivo». Pragmática Sociocultural 2 (2), 223-26I. Recuperado de http://www.degruyter.com/view/j/soprag

Alcaide Lara, E. R. (en este volumen). «Discursos populistas en la política española actual: el caso de Podemos y Ciudadanos».

Bernal, M. (2007). Categorización sociopragmática de la cortesía y descortesía. Un estudio de la conversación coloquial española. Tesis doctoral, Stockholms Universitet.

Bernal, M. (2016). «Autoimagen e imagen de rol en el metadiscurso parlamentario: Iglesias (Podemos) vs. Villalobos (PP)», en D. Dumitrescu \& D. Bravo (eds.), Actividades de imagen y situación comunicativa en discurso en español. Buenos Aires: Editorial Dunken, 9I-I39.

Bolívar, A. (2005). «Descortesía y confrontación política», in D. Bravo (ed.), Estudios de la (des) cortesía en español. Categorías conceptuales y aplicaciones a corpora orales y escritos. Buenos Aires: Editorial Dunken, 273-297.

Blas Arroyo, J. L. (2000). "'Mire usted Sr. González...' Personal deixis in Spanish political-electoral debate». Journal of Pragmatics 32, I-27.

Bravo, D. (I996). La risa en el regateo: Estudio sobre el estilo comunicativo de negociadores. Tesis doctoral, Stockholms universitet.

Bravo, D. (I999). «¿Imagen «positiva» vs. imagen «negativa»? Pragmática socio-cultural y componentes de face». Oralia 2, I 5 5-I 84.

Bravo, D. (2002). «Actos asertivos y cortesía: Imagen del rol en el discurso de académicos argentinos", en D. Bravo \& M. E. Placencia (eds.), Actos de habla y cortesía en el español. Munich: Lincom Europa, I4I-I74.

Bravo, D. (2005). "Categorías, tipologías y aplicaciones: hacia una redefinición de la cortesía comunicativa», en D. Bravo (ed.), Estudios de la (des) cortesía en español. Categorías conceptuales y aplicaciones a corpora orales $y$ escritos. Buenos Aires: Dunken, 2 I-52.

Brown, P. \& Levinson, S. (1978, 1987). Politeness. Some Universals in Language Use. Cambridge: Cambridge University Press. 
Charaudeau, P. (2005). Le discours politique. Les masques du pouvoir. Paris: Vuibert.

Charaudeau, P. (2009). «La argumentación persuasiva. El ejemplo del discurso político», en M. Shiro, P. Bentivoglio \& F. de Erlich (eds.), Haciendo discurso. Homenaje a Adriana Bolivar. Caracas: Comisión de Estudios de Postgrado-Facultad de Humanidades y Educación, Universidad Central de Venezuela, 277-295.

Chafe, W. L. (I979). "The flow of thought and the flow of language», in Talmy Givón (ed.), Syntax and Semantics I2. Discourse and sintax. New York: Academic Press, I 59-I 82.

Chafe, W. L. (I980). "The deployment of consciousness in the production of a narrative», en W. Chafe (ed.), The pear stories: Cognitive, cultural, and linguistic aspects of narrative production. Norwood, NJ: Ablex, IO-50.

Fauconnier, G. (I985). Mental spaces: aspects of meaning construction in natural language. Cambridge: MA, MIT Press.

Goffman, E. (I967). Interactional ritual: Essays face-to-face behaviour. New York: Pantheon.

Goffman, E. (I974). Frame analysis. New York: Harper and Row.

Hernández Flores, N. (2002). La cortesía en la conversación española de familiares y amigos; la búsqueda del equilibrio entre la imagen del hablante y la imagen del destinatario. Tesis doctoral, Institut for Sprog Internationale Kurturstudier, Aalborg universitet, 37.

Hernández Flores, N. (2013a). «Actividad de imagen: caracterización y tipología en la interacción comunicativa». Pragmática Sociocultural I(2), I75I98. Recuperado de http://www.degruyter.com/view/j/soprag

Hernández Flores, N. (2013b). «The use of personal deixis as an ideological instrument in Spanish political discourse», en K. Kragh \& J. Lindschouw (eds.), Deixis and Pronouns in Romance Languages. Amsterdam/ Philadelphia: Benjamins, I7 I-I 88 .

Hernández Flores, N. (2015). «Blogs and construction of a new political candidate's identity. The blog of the Spanish politician Pablo Iglesias». Comunicación presentada en Ist International Conference: Approaches to Digital Discourse Analysis ADDA I. Valencia, I9-20 de noviembre de 2015.

Hernández Flores, N. \& Gómez Sánchez, M. E. (20I4). «Actividades de imagen en la comunicación mediática de medidas políticas contra la crisis: el copago sanitario". Revista de Filología de la Universidad de La Laguna 32: I2 5-I 44. Recuperado de https://riull.ull.es/xmlui/bitstream/handle/9 I 5/4644/RF_32_ \%2820I4\%29_06.pdf? sequence= I \&isAllowed =y 
Mariottini, L. (2015). "'El enemigo está en el Norte'. La construcción discursiva de la crisis económica española en la prensa nacional conservadora», en D. Bravo \& M. Bernal (eds.), Perspectivas sociopragmáticas y socioculturales del análisis del discurso. Buenos Aires: Programa EDICE-Dunken, $23-48$.

Pano Alamán, A. (20 I 5). «Ironía verbal y actividad de imagen en el discurso de políticos y ciudadanos españoles en Twitter». Pragmática Sociocultural 3(I), 59-89. Recuperado de http://www.degruyter.com/view/j/soprag

Van Dijk, T. (2006). «Ideology and discourse analysis». Journal of Political Ideologies I I(2), I I 5-I 40.

Zupnik, Y. (I994). "A pragmatic analysis of the use of person deixis in political discourse». Journal of Pragmatics 2 I, 339-283.

Ærstrøm, S. O. (2015). En pragmatisk-diskursiv analyse af Pablo Iglesias Turrións brug af uhøflighed $i$ den politiske debat. Tesis de maestría, Institut for Engelsk, Germansk og Romansk, Københavns universitet. 
